\title{
Review on the cost optimization of microgrids via particle swarm optimization
}

\author{
Sengthavy Phommixay ${ }^{1}\left[\right.$ Mamadou Lamine Doumbia $^{1} \cdot$ David Lupien St-Pierre $^{2}$
}

Received: 15 July 2019 / Accepted: 14 December 2019 / Published online: 27 December 2019

(c) The Author(s) 2019

\begin{abstract}
Economic analysis is an important tool in evaluating the performances of microgrid (MG) operations and sizing. Optimization techniques are required for operating and sizing an MG as economically as possible. Various optimization approaches are applied to MGs, which include classic and artificial intelligence techniques. Particle swarm optimization (PSO) is one of the most frequently used methods for cost optimization due to its high performance and flexibility. PSO has various versions and can be combined with other intelligent methods to realize improved performance optimization. This paper reviews the cost minimization performances of various economic models that are based on PSO with regard to MG operations and sizing. First, PSO is described, and its performance is analyzed. Second, various objective functions, constraints and cost functions that are used in MG optimizations are presented. Then, various applications of PSO for MG sizing and operations are reviewed. Additionally, optimal operation costs that are related to the energy management strategy, unit commitment, economic dispatch and optimal power flow are investigated.
\end{abstract}

Keywords Cost minimization $\cdot$ Particle swarm optimization $\cdot$ Operations $\cdot$ Sizing $\cdot$ Microgrid $\cdot$ Renewable energy

\section{Introduction}

\section{Microgrid description}

Microgrids (MGs) have provided substantial motivation for the development of a smarter, more resilient and cost-effective approach for producing energy. MGs are mainly constructed from renewable energy sources (RESs) by focusing on the independence of local energy supplies, as illustrated in Fig. 1. Distributed energy resources (DERs), which are also known as distributed generation (DG), can be combinations of conventional energy sources, such as diesel units (DUs) and combustion gas turbines, and RESs, such as wind turbines (WTs) and photovoltaics (PVs). The integration of groups of DERs and energy storage systems (ESSs) such as

Sengthavy Phommixay

sengthavy.phommixay@uqtr.ca

1 Department of Electrical and Computer Engineering, Université du Québec à Trois-Rivières, 3351 Boulevard des Forges, Trois-Rivières, QC G9A 5H7, Canada

2 Department of Industrial Engineering, Université du Québec à Trois-Rivières, 3351 Boulevard des Forges, Trois-Rivières, QC G9A 5H7, Canada batteries, capacitors, hydrogen, and flywheels, with loads that are interconnected by a local electric power distribution system, is called an MG [1-3]. Hybrid renewable energy systems (HRESs) consist of a group of two or more RESs and conventional energy sources and are often referred to as MGs [4-6].

An MG, DER or HRES can take the form of an AC, DC or hybrid $\mathrm{AC}-\mathrm{DC}$ network depending on the generation sources or load connections. The characteristics of AC, DC and hybrid AC-DC networks are compared in [7, 8]. Furthermore, various ESS technologies and MG control types are presented in [7]. The authors in [9] have classified MGs in four scales, as listed in Table 1.

An MG encourages the integration of RESs to realize the objective of sustainable development. This improves the reliability, efficiency, and security of power supply systems. An MG can connect to the grid (in grid-connected mode) or operate independently without a grid connection (as an islanded grid, off-grid, standalone grid, or autonomous grid).

The main economic issue for MGs is the efficient utilization of renewable and conventional energy sources. The energy cost is minimized by tuning the size and operations of MGs [1, 10-12]. The authors in [10] provide an approach for realizing an optimal operation and sizing 
Fig. 1 MG architecture

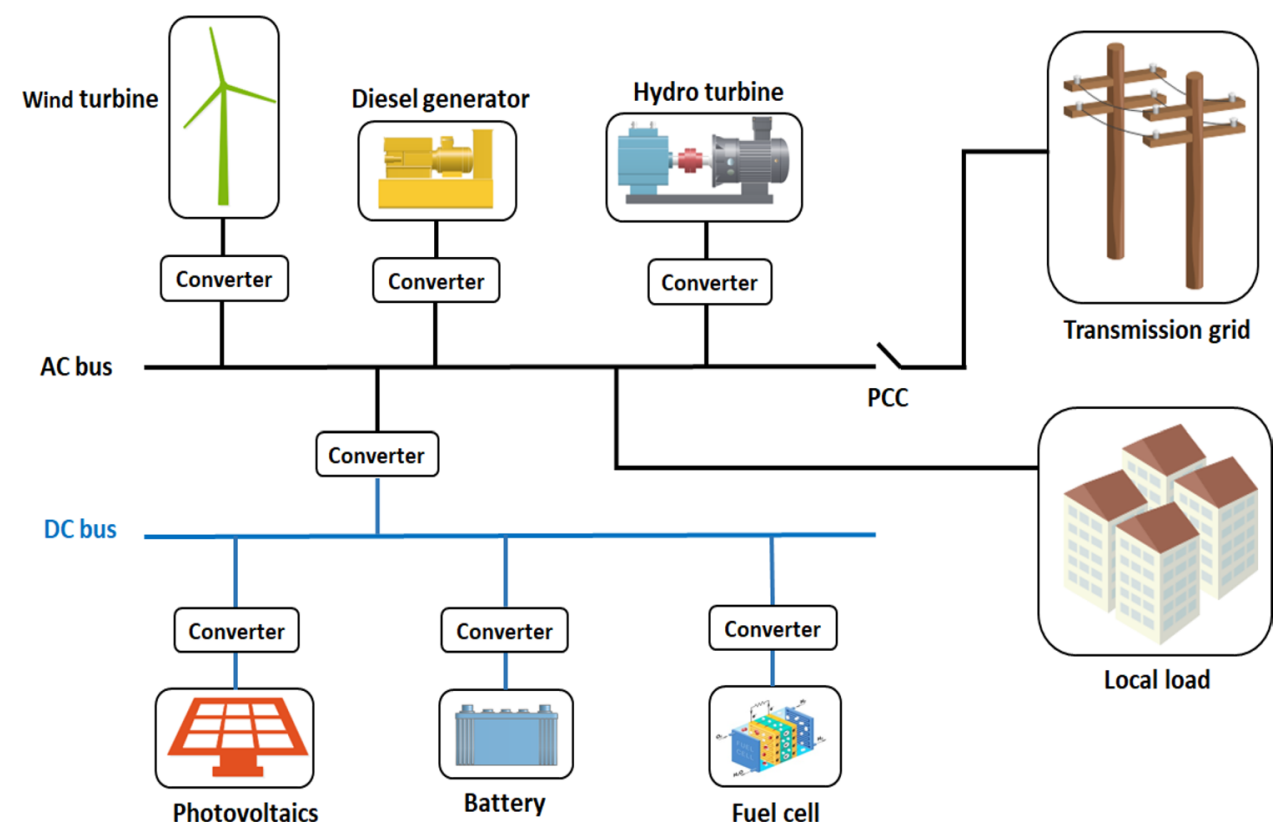

Table 1 MG scale classification

\begin{tabular}{ll}
\hline Scale & Power \\
\hline Micro & $1 \mathrm{~W}-5 \mathrm{~kW}$ \\
Small & $5 \mathrm{~kW}-5 \mathrm{MW}$ \\
Medium & $5 \mathrm{MW}-50 \mathrm{MW}$ \\
Large & $50 \mathrm{MW}-300 \mathrm{MW}$ \\
\hline
\end{tabular}

of an MG that guarantees the minimum energy cost. In [11], the authors demonstrate the influence of the size on the operational cost. Small sources and storage may not provide economic benefits, flexibility or reliability in an MG. However, large sources and storage require higher investment and incur higher maintenance costs [12]. Thus, it is highly important to know how the MG operates when sizing the system. The optimal size is found when the energy cost is minimized and may be subject to technical and environmental constraints. Furthermore, the minimum energy cost is made possible by energy management strategy (EMS), unit commitment (UC), economic dispatch (ED) and optimal power flow (OPF), which are parts of an optimal operation strategy. The uncertainties of renewable energy sources may affect the cost-benefits of MGs. Thus, it is difficult for grid operators to control and manage these energy sources. Renewable power forecasting is an important task for the grid operator for enhancing the effectiveness of the grid operation. Furthermore, renewable power forecasting has attracted attention from academic research communities [13] since it can play an important role in identifying the optimal operation [14].
Table 2 Optimization techniques

\begin{tabular}{ll}
\hline Classical methods & Artificial intelligence methods \\
\hline Linear programming (LP) & Artificial neural network (ANN) \\
Nonlinear programming (NLP) & Fuzzy logic method (FL) \\
Newton-Raphson (NR) & Genetic algorithm (GA) \\
Quadratic programming (QP) & Evolutionary programming (EP) \\
Interior point (IP) & Ant colony optimization (ACO) \\
& Particle swarm optimization (PSO) \\
& Dynamic programming (DP) \\
& Bacterial foraging optimization \\
& (BFO) \\
& Simulated annealing (SA) \\
& Differential evolution (DE) \\
\hline
\end{tabular}

\section{Optimization techniques}

Without optimization techniques, the cost-benefit of an MG may not be justified. Optimization aims at identifying the best alternative from a set of specified solutions that are the most cost-effective or have the highest realizable performance under the specified constraints. Many approaches are available for addressing optimization problems when classic optimization techniques are unable to find an optimal solution. Artificial intelligence (AI) is a promising method for cost optimization. The main advantage of AI is the ability to combine more than one method: first, in finding the best primary solution and subsequently, finding a better solution.

Table 2 lists various optimization techniques that are used to identify the most feasible solution to the problem of cost minimization in MGs [15-17]. 
Various optimization techniques, such as PSO for MG sizing, are applied in [18]. The authors discuss the convergence speeds of and the quality of the solutions that are derived by various methods. Another application of optimization techniques is presented in [19], namely, finding the optimal parameters of the Weillbul distribution for wind turbine projects in Brazil. In this study, the authors compare the performances of heuristic algorithms with deterministic numerical methods.

A review of various optimization techniques and sizing methods of MG systems is presented in [20]. This paper presents a comprehensive study on finding the best compromise between the MG cost and the system reliability. In another review [6], the authors discuss sizing methodologies for both isolated and grid-connected MGs. Sizing criteria that are related to the operating costs, reliability and loads are investigated. Reference [21] reviews sizing strategies that are based on optimization techniques. It also presents a cost analysis and a reliability index that are used in MG sizing. In [22], the authors focus on optimization techniques for optimal MG sizing. In addition, optimization techniques and computer tools for MG sizing are analyzed. The authors in [23] present an overview of the optimization techniques for MG sizing, placement and design, in which they highlight the successful application of PSO, whereas the authors in [24] focus on optimization techniques and tools that are used for optimal operation and deployment of MGs. In this review, many objective functions are presented for various types of operations and renewable energy sources. The authors in [25] discuss the application of optimization techniques for finding the optimal sizes and operation schedules of MGs. This review focuses on the ED problem for investigating operation scheduling.

Various reviews have been conducted on optimization techniques for MG sizing in the aforementioned studies; only a few reviews examine the optimization techniques for $\mathrm{MG}$ sizing, including the optimal operation of MGs. In addition, the optimization techniques are discussed with little detail. No analysis of the efficiency, robustness, or flexibility of the algorithms is provided. However, an optimization technique is required for MG sizing and operations and for enhancing the reliability, environmental effects, and component lifetime.

In this paper, we consider the PSO algorithm and its application to MG optimization. Additionally, we explain how the performance analysis and the selection of parameters and stopping criteria of the PSO algorithm are conducted. To the best of the authors' knowledge, this is the first attempt to identify both the optimal operation and size of an MG via the PSO algorithm. We investigate various types of operations, such as EMS, UC, ED, and OPF. In addition, the cost optimization of the operations and size are outlined. We summarized various objective functions and constraints equations for MG optimization. We classify the cost function type, and linear, quadratic and cubic models, along with smooth and nonsmooth models, are discussed. The comprehensiveness of these models leads to as high of a performance in PSO implementation as any other algorithms.

The remainder of the paper is organized as follows: in Sect. 2, MG cost optimization is presented. Additionally, the versions and combination methods of PSO that are used for MG optimization are described. Section 3 describes the mathematical model for the cost analysis of the MG. Section 4 presents the cost-benefit that is related to the size of the MG. Finally, the cost-benefits that are related to the operations are presented in Sect. 5.

\section{MG cost optimization}

Optimization is the procedure of finding the minimum or maximum value of a function by choosing variables, subject to constraints. The optimization function is called the fitness or objective function and is typically calculated using simulation tools.

An optimization method is not always guaranteed to find an optimal solution. Sometimes, this can be unrealized due to the characteristics of the problem. The choice of an optimization technique depends on the type of the cost function to be solved. According to the authors in [26, 27], some techniques are unable to deal with nonsmooth and nonconvex optimization. These techniques have difficulty handling inequality constraints.

PSO is a robust optimization technique and is applied in various applications of MGs. It can solve continuous and discrete optimization problems. In addition, it is simple to implement, flexible and computes quickly. PSO is the most frequently used method for MG optimization problems [23]; consequently, approximately 70 research papers that are based on PSO have been studied in this work.

\section{- Classic version of PSO}

PSO is based on a swarm (population) of $N$ particles. These particles are randomly placed in the search space $D$. Each particle $i$ of the swarm is defined by its position $X_{i j}=\left(X_{i 1}, X_{i 2}, \ldots, X_{i D}\right)$ and its velocity $V_{i j}=\left(V_{i 1}, V_{i 2}, \ldots\right.$, $\left.V_{i D}\right)$ in the search space $D$. Index $i$ varies from 1 to $N$, and index $j$ varies from 1 to $D$.

The particles move at each iteration by considering their best position and the best position of their neighborhood. The velocity and position equations are presented as follows: 


$$
\begin{aligned}
\text { Velocity } V_{i j}^{k+1}= & w \cdot V_{i j}^{k}+c_{1} \cdot r_{1} \cdot\left(P_{\text {best }}-X_{i j}^{k}\right) \\
& +c_{2} \cdot r_{2} \cdot\left(G_{\text {best }}-X_{i j}^{k}\right)
\end{aligned}
$$

Position $X_{i j}^{k+1}=X_{i j}^{k}+V_{i j}^{k+1}$,

where $w$ is the inertia weight, $c_{1}$ and $c_{2}$ are the acceleration coefficients, and $r_{1}$ and $r_{2}$ are random numbers between 0 and $1 . X_{i j}^{k}$ is the position of the $i$ th particle in the $j$ th dimension in the $k$ th iteration. $V_{i j}^{k}$ is the velocity of the $i$ th particle in the $j$ th dimension in the $k$ th iteration. $P_{\text {best }}$ is the personal best position, and $G_{\text {best }}$ is the global best position. $V$ can be limited to $\left[-V_{\max }, V_{\max }\right]$, where $V_{\max }$ is the maximum velocity limit. $X$ is limited to [ $X_{\min }$, $X_{\max }$, where $X_{\min }$ and $X_{\max }$ are the minimum and maximum particle position limits, respectively. $k$ varies from 1 to Maxite, where Maxite is the total number of iterations. The procedure of PSO is illustrated in Fig. 2.

The choice of parameters and stopping criteria influences the performance of the PSO algorithm. If suitable parameters and stopping criteria are selected, the algorithm can provide a better result.

- Parameter selection

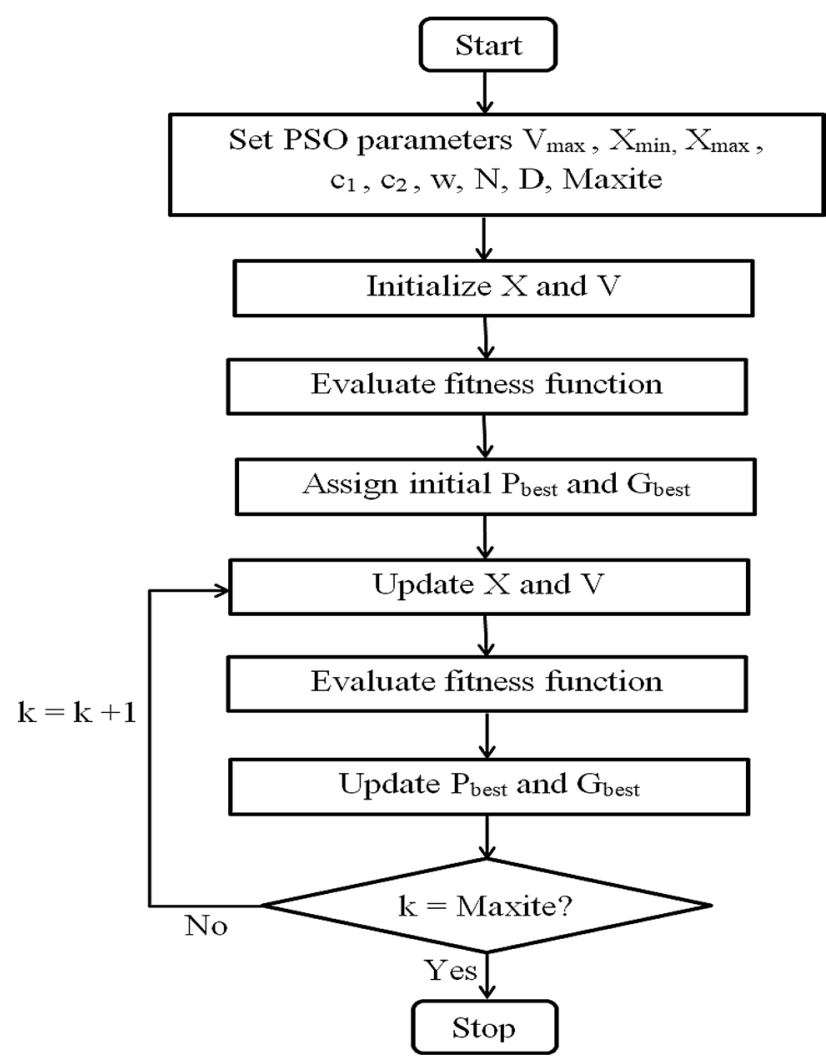

The optimization parameters determine the performance of the algorithm in searching for the global optimum of a problem. The selection of these parameters is a crucial step in the optimization process. The analysis of each parameter selection is described as follows:

- Number of particles $(N)$ : if the number of particles is small, it can influence the performance of PSO. If we increase the number of particles, we can decrease the number of iterations. Thus, the algorithm can still find an optimal solution.

- Acceleration coefficients $\left(c_{1}\right.$ and $\left.c_{2}\right)$ : the acceleration coefficients $c_{1}$ and $c_{2}$ guide the particles to move toward $P_{\text {best }}$ and $G_{\text {best }}$, respectively. Small values may limit the particle movements toward a satisfactory solution. However, a large value may lead the particles to move away from the solution.

- Maximum velocity $\left(V_{\max }\right)$ : the particle velocity is typically restricted within a specified range to prevent the particles from moving away from the search space. If $V_{\max }$ is too small, the particles may only explore the local best, whereas if $V_{\max }$ is too large, then the particles may pass over a satisfactory solution.

- Inertia weight $(w)$ : the inertia weight balances the local and global explorations. A large inertia weight provides a strong global search, whereas a small inertia weight provides a strong local search. The value of the inertia weight can change during the optimization process. Therefore, self-adaptive approaches that modify the value of inertia weight during the search procedure are recommended in the literature.

- Stopping criterion

The stopping criterion is fundamental in PSO optimization because the algorithm must not terminate prior to reaching the global optimum. However, the algorithm must automatically terminate when the optimal solution is found to avoid wasting computational resources during the execution. Therefore, the choice of stopping criterion has a large influence on the duration of the optimization processes. Many stopping criteria are presented in the literature, such as a tolerance, the number of function evaluations, and the maximum number of iterations.

- Binary version of PSO (BPSO)

In the binary version of PSO, a particle represents the position in binary space and the particle's position vectors can take on a binary value 0 or 1 . The same equation as that for the classic version of PSO is used to update the velocity. The equation for updating a particle position is:

Fig. 2 Flowchart of PSO 
$x_{i j}^{k}=\left\{\begin{array}{lll}1 & \text { if } & u_{i j}^{k}<s_{i j}^{k} \\ 0 & \text { if } & u_{i j}^{k} \geq s_{i j}^{k}\end{array}\right.$,

where $u_{i j}^{k}$ is a random number between 0 and 1 , and $s_{i j}^{k}$ is the sigmoid function.

Sigmoid function $s_{i j}^{k}=\frac{1}{1+\mathrm{e}^{-v_{i j}^{k}}}$.

The velocity $V_{i j}^{k}$ is limited within the range $\left[-V_{\max }\right.$, $\left.V_{\max }\right]$. These bounds correspond to the probabilities for the particle position $x_{i j}^{k}$ to change to 0 and 1 . The maximum velocity $V_{\max }=5$ corresponds to a maximum probability for a particle to be 1 . The minimum velocity $V_{\min }=-5$ corresponds to a minimum probability for a particle to be 0 .

- Many versions of PSO have been introduced in [28, 29] and are summarized as follows:

- Modifications of PSO: quantum-behaved PSO, barebones PSO, chaotic PSO, fuzzy PSO, PSO timevarying acceleration coefficient, opposition-based PSO, topology, improved PSO, adaptive PSO, and mutation PSO, among others.

- Combinations of PSO with other metaheuristic methods (hybrid PSO): GA, evolutionary programming, artificial immune system (AIS), tabu search (TS), ACO, simulated annealing (SA), artificial bee colony $(\mathrm{ABC}), \mathrm{DE}$, biogeography-based optimization (BBO), harmonic search (HS), Lagrange relaxation (LR), and guaranteed convergence PSO with Gaussian mutation (GPSO-GM), among others.

- Extensions of PSO: multi-objective, constrained, combinatorial, and discrete (binary and integer) optimization, among others.

The evaluation of the performance of the algorithm is typically recommended for all optimization problems. We should be able to demonstrate that the selected algorithm provides a superior solution faster than other algorithms. Here, we provide insight into the performance analysis:

- Effectiveness

The effectiveness consists of the computational effort and the quality of the solution.

- Computational effort: the computational effort is the required time for the algorithm to converge to an optimal solution. The parameters that significantly influence the computational effort of PSO are the swarm size and the number of iterations. The computational effort can also refer to various terms such as the time for reaching the optimal solution, the time for computing each iteration, and the total running time (or the time for computing all iterations).

- Quality of the solution: the quality of the solution refers to the closeness of the solution to the optimal solution. If the optimal solution is unknown, it is difficult to evaluate the quality of the solution. This is a common issue when dealing with optimization techniques. In this regard, comparison with a published solution or with a solution that was obtained via another technique is typically required.

- Robustness

Robustness is an important criterion for evaluating the performance of an algorithm. It refers to the ability of an algorithm to reach an optimal solution for any instance of various test problems. A robust algorithm must also be relatively insensitive to the parameter values. When the parameters are selected, the measurement of the sensitivity to the small changes in the parameter values is useful for investigating the robustness.

- Flexibility

PSO is a flexible method that can solve all complex optimization problems. Many definitions are used to define flexibility. In our work, we define flexibility as the adaptiveness of the algorithm, as it can automatically adjust and adapt to consider the uncertainties and to generate the best possible solutions.

Implementation issues can influence the computational effort of the algorithm. Thus, the choices of programming language, libraries, and compiler play a significant role in enhancing the optimization performance, especially in terms of the computational effort. Moreover, the computer characteristics (such as the processor and RAM) and the operating system are important for performing a variety of tasks with high computational performance. The engineers must weigh various choices and identify the solutions that best satisfy the requirements. Furthermore, the engineers must identify the available resources to solve an optimization problem efficiently.

\section{Offline and online optimizations}

Offline and online optimizations are required for enhancing MG operations in terms of the power demand, renewable energy resources, and economic aspects.

- Offline optimization: power management is typically formulated as an offline optimization problem. This approach is based on a priori knowledge of the weather conditions and a pre-established load profile. This strategy is also used to evaluate the quality of real-time EMS 
since it determines the theoretical minimum realizable energy cost.

- Online optimization (real-time optimization): the load profile, weather conditions, and fuel costs change over time. Real-time optimization is needed to identify the optimal solution regardless of the variation of these parameters. However, the implementation of online algorithms requires a performance computation tool for evaluating the problem in each time interval, especially when the time step is short.

\section{Objective functions}

\section{Single-objective function}

In single-objective-function optimization, a single-objective function is minimized or maximized. The following parts summarize the objective functions that are typically implemented in MG optimization:

- Minimize

- Life cycle costs [30]

- Gas emissions $\left(\mathrm{CO}_{2}, \mathrm{NO}_{x}, \mathrm{SO}_{2}, \mathrm{PM}_{2.5}\right.$, and $\left.\mathrm{PM}_{2.5-10}\right)$ [31-33]

- Power losses (active and reactive losses) [34-36]

- Lifetime degradation [37-39]

- Maximize

- Benefits or profits [40-42]

- Reliability: by minimizing the loss of power supply probability (LPSP), loss of load probability (LLP/ LOLP), unmet load (UL), system performance level (SPL), loss of load hours (LLH), loss of load risk (LOLR), or level of autonomy (LA) [33, 43, 44]
- Power generation [45, 46]

- Loadability [47]

- Net present value [33]

\section{Multi-objective function}

When there is only one criterion to be optimized, an optimization problem is described as a single-objective-function optimization problem. In other cases, there are several criteria to be optimized simultaneously; such an optimization problem is described as a multi-objective optimization problem.

Multi-objective optimization (MOO) problems consist of several objectives that must be realized simultaneously. MOO is the process of finding a compromise among conflicting objective functions. Reference [24] summarizes various multi-objective optimizations that are applied in $\mathrm{MG}$, which are listed in Table 3.

\section{Optimization constraints}

\section{Equality constraint}

- Power balance: the total power that is generated should match the load demand.

$P_{\text {load }, t}=\sum_{i}^{N} P_{i, t}$,

where $P_{\text {load }}$ is the load power, $N$ is the total number of generating units, $P_{i}$ is the power output of the $i$ th generating unit and $t$ is the time.
Table 3 Multi-objective optimizations

\begin{tabular}{lll}
\hline First objective function & Second objective function & References \\
\hline Maximization of revenue & Minimization of emissions & {$[48]$} \\
& Maximization of reliability & {$[49]$} \\
Minimization of operating costs & Maximization of reliability & {$[50-55]$} \\
& Minimization of emissions & {$[56-62]$} \\
& Maximization of components lifetimes or & {$[63,64]$} \\
& minimization of lifetime degradation & \\
& Maximization of power availability & {$[65]$} \\
& Maximization of profit & {$[66,67]$} \\
& Maximization of reliability & {$[52,53,68,69]$} \\
& Minimization of emissions & {$[58,60,70]$} \\
& Minimization of fuel consumption & {$[30]$} \\
& Minimization of operating cost & {$[71]$} \\
\hline
\end{tabular}




\section{Inequality constraints}

- Rate power unit: the power output of each generating unit must be within its minimum $\left(P_{\min }\right)$ and maximum limits $\left(P_{\max }\right)$.

$P_{i, \text { min }} \leq P_{i, t} \leq P_{i, \max }$.

- Ramp rate power limit: these constraints determine the maximum variation of the power output for each unit [72].

$P_{i, t}-P_{i, t-1} \leq R U_{i}$

$P_{i, t-1}-P_{i, t} \leq R D_{i}$,

where $R U_{i}$ is the ramp-up limit and $R D_{i}$ is the ramp-down limit of the $i$ th unit.

- Minimum uptime/maximum downtime: these constraints specify a minimum time for each unit to be maintained before it can change its status $[72,73]$.

If the unit is turned on, there will be a minimum running time before it can be shut down:

$T_{t}^{\mathrm{on}}-M U T \geq 0$,

where $T_{t}^{\mathrm{on}}$ is the duration for which the unit is continuously $\mathrm{ON}$, and $M U T$ is the minimum uptime.

Once a unit has been shut down, it may not be turned back on immediately:

$T_{t}^{\text {off }}-M D T \geq 0$,

where $T_{t}^{\text {off }}$ is the duration for which the unit is continuously $\mathrm{OFF}$, and $M D T$ is the minimum downtime.

- Maximum start/stop limits: the maximum number of starts/stops should be included in the optimization process. This depends on the generation unit and the operator [74].

$S_{\text {start/stop }} \leq N_{\max }$,

where $S_{\text {start/stop }}$ is the number of starts/stops during the simulation time, and $N_{\max }$ is the maximum number of start/stop sequences.

\section{Cost functions that are related to MG operations and sizing}

In this section, cost functions that are related to operations and sizing are presented. Various cost definitions and equations were reported in a previous research paper
[75]. Here, we summarize those that are most frequently used in the literature.

(a) Initial investment cost (IC): this consists of the initial costs for unit installation [76].

$I C=\sum C_{\mathrm{inv}, i} \cdot P_{i}$,

where $C_{\mathrm{inv}, i}$ is the investment cost of the $i$ th unit ( $\$$ / $\mathrm{kW})$, and $P_{i}$ is the output power of the $i$ th unit.

(b) Replacement cost $(R C)$ : this cost is incurred since the lifespans of the units differ from the project duration $[77,78]$.

$R C=\sum C_{\mathrm{rep}, i} \cdot S F F_{i}$,

$S F F_{i}$ is the sinking factor:

$S F F_{i}=\frac{r}{(1+r)^{t}-1}$,

where $C_{\text {rep }, i}$ is the replacement cost of the $i$ th unit, $r$ is the interest rate of the $i$ th unit, and $t$ is the lifetime of the $i$ th unit.

(c) Capital cost (CC): the capital cost for MG power generation and energy storage includes the cost of the equipment and the costs that are associated with its installation [78].

$C C=\sum\left(C_{\mathrm{inv}, i} \cdot P_{i}\right) \cdot C R F_{i}$,

$C R F_{i}$ is the capital recovery factor of the $i$ th unit, which is expressed as follows:

$C R F_{i}=\frac{r \cdot(1+r)^{y}}{(1+r)^{y}-1}$,

where $r$ is the interest rate and $y$ is the lifetime of the system.

(d) Levelized cost of electricity ( $L C O E)$ : the $L C O E$ is the total cost of the installation, replacement, fueling, and maintenance of an MG. It represents the price of electricity per kWh over the system's life. A low LCOE corresponds to a low electricity cost $[44,77,79,80]$.

$L C O E=\left(\frac{M C+I C+R C+F C}{E}\right)$,

where $E$ is the annual energy output of the system, $M C$ is the maintenance cost, $I C$ is the investment cost, $R C$ is the replacement cost, and $F C$ is the fuel cost.

(e) Maintenance cost $(M C)$ : the $M C$ is typically related directly to the power output. It is assumed to have a proportional relationship with the power that is produced $[77,78]$. 
$M C=\sum K O M_{i} \cdot P_{i} \cdot \Delta T$,

where $K O M_{i}$ is the proportionality constant $(\$ / \mathrm{kWh})$ of the $i$ th unit, $P_{i}$ is the output power of the $i$ th unit, and $\Delta T$ is the sampling time.

(f) Emission reduction benefit $(E R B)$ : compared to traditional generators, renewable energy is clean and pollution-free, thereby reducing the cost of the system in terms of environmental protection throughout the life cycle [77].

$E R B=\sum_{i=1}^{4}\left(E_{\mathrm{out}}-E_{\mathrm{buy}}\right) \cdot C_{\mathrm{emis}, i} \cdot C_{\mathrm{env}, i}$,

where $E_{\text {out }}$ is the energy output of the unit, $E_{\text {buy }}$ is the purchased energy from the grid, $C_{\text {emis }}$ is the emission value of the $i$ th type of greenhouse gas, and $C_{\mathrm{env}}$ is the environmental cost of the $i$ th type of greenhouse gas.

(g) Start-up cost: the start-up cost of each unit depends on the duration for which the unit has been shut down and is expressed as follows [73]:

$S T C=\sum a_{i}+b_{i} \cdot\left(1-\exp \left(\frac{-T_{\mathrm{off}}}{T_{i}}\right)\right)$,

where $a_{i}$ is the hot start-up cost of the $i$ th unit, $b_{i}$ is the cold start-up cost, $T_{\text {off }}$ is the duration for which the $i$ th unit has been continuously shut down, and $T_{i}$ is the cooling time of the $i$ th unit.

(h) Net present cost $(N P C): N P C$ can be referred to as the life cycle cost. It is defined as the sum of the capital, maintenance, fuel and replacement costs [81, 82].

$N P C=\left(C C+R C+M C \times \frac{1}{C R F}\right)$,

where $C C$ is the capital cost, $R C$ is the investment cost, $M C$ is the maintenance cost, and $C R F$ is the capital recovery factor.

(i) Fuel costs

There are many characteristics of fuel cost functions, which can be represented as follows:

- Smooth model

Smooth cost functions can be represented as first-order equations (linear models), second-order equations (quadratic models), or third-order equations (cubic models). These cost functions are plotted in Fig. 3 and are formulated as follows $[83,84]$ :

- First-order function (linear model)

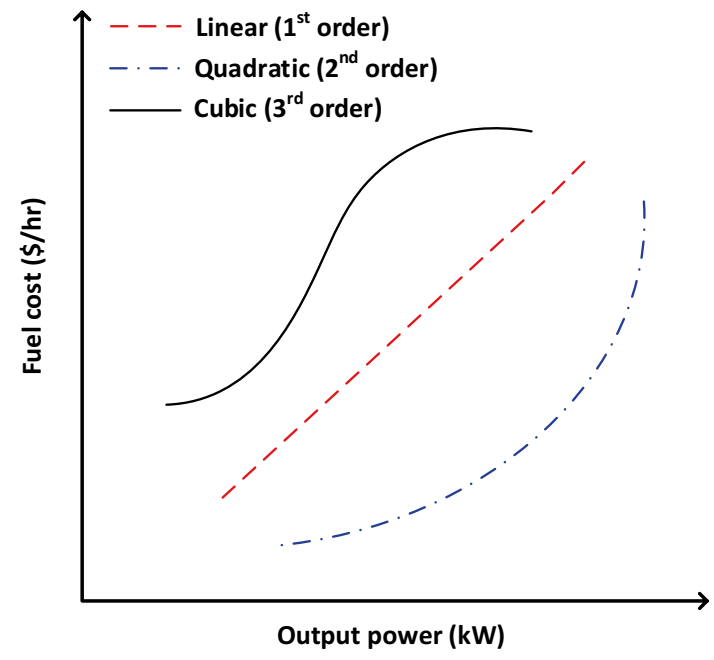

Fig. 3 Fuel cost function

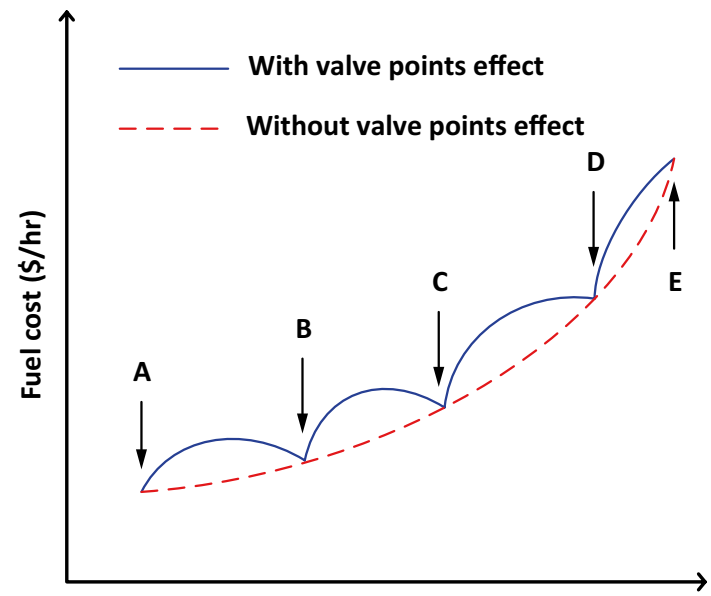

Output power (kW)

Fig. 4 Valve-point cost function with 5 valves: a primary valve. b Secondary valve. c Tertiary valve. d Quaternary valve. e Quinary valve

$F C_{i}\left(P_{i}\right)=a_{i} P_{i}+b_{i}$

- Second-order function (quadratic model)

$F C_{i}\left(P_{i}\right)=a_{i} P_{i}^{2}+b_{i} P_{i}+c_{i}$

- Third-order function (cubic model)

$F C_{i}\left(P_{i}\right)=a_{i} P_{i}^{3}+b_{i} P_{i}^{2}+c_{i} P_{i}+d_{i}$

where $a, b, c$ and $d$ are the fuel cost coefficients and $P_{i}$ is the generated power of the $i$ th unit. 
- Nonsmooth model

In Fig. 4, a cost function with the valve point effect is plotted. In practical operations, steam turbines have many steam valves that control the power that is generated. The opening of these valves causes losses in the generation unit, thereby resulting in ripple effects on the input-output characteristic cost function. This feature makes the cost model nonsmooth. A sinusoidal function that represents the valve point effect is added to the quadratic cost function and is modeled as $[84,85]$ :

$F C_{i}\left(P_{i}\right)=a_{i} P_{i}^{2}+b_{i} P_{i}+c_{i}+\left|e_{i} \cdot \sin \left(f_{i}\left(P_{i}^{\min }-P_{i}\right)\right)\right|$,

where $e_{i}$ and $f_{i}$ are coefficients that are related to valve points of the $i$ th generation unit, and $P_{i}^{\min }$ is the minimum power limit of the $i$ th generation unit.

\section{- Nonconvex model}

Optimization problems can be divided into two types according to the fuel cost function: convex and nonconvex problems. In a convex problem, the fuel cost function does not consider the valve point effect and is expressed as a quadratic function. The fuel cost function in a nonconvex problem considers the following elements: prohibited operating zones, valve-point loading effects, and combined valve-point loading effects and multi-fuel options [86-92].

The prohibited operating zones represent the limitations on the power output of the unit that are caused by vibrations in a shaft bearing or steam valve operation. Thus, operation is not allowed in such regions to avoid damage to the unit and to realize the most economical operation [91]. A cost function with prohibited operating zones is plotted in Fig. 5.
$P_{i}^{\min } \leq P_{i} \leq P_{i, 1}^{l}$

$P_{i, j-1}^{u} \leq P_{i} \leq P_{i, j}^{l} \quad j=2,3, \ldots, n_{i}$

$P_{i, n_{i}}^{u} \leq P_{i} \leq P_{i}^{\max }$

where $j$ represents the number of prohibited operating zones of the $i$ th unit, $n_{i}$ is the total number of prohibited operating zones of the $i$ th generating unit, $P_{i, j-1}^{u}$ is the upper limit of the $(j-1)$ th prohibited operating zone of the $i$ th unit, and $P_{i, j}^{l}$ is the lower limit of the $j$ th prohibited operating zone of the $i$ th unit [88].

For a power plant with many generators and fuel types for each unit, the fuel cost function for fuel type $j$ of the $i$ th unit is plotted in Fig. 6 and is expressed as:

$F C_{i j}\left(P_{i}\right)=a_{i j} P_{i}^{2}+b_{i j} P_{i}+c_{i j}+\left|e_{i j} \cdot \sin \left(f_{i j}\left(P_{i j}^{\min }-P_{i}\right)\right)\right|$.

\section{Implementation of PSO for cost minimization in MG sizing}

Among the various factors that influence the behavior of an MG, optimal sizing is of particular interest in MG optimization for determining the minimum cost of the system. In an isolated MG, sizing is more difficult than in a grid-connected MG since it must operate continuously without any support from the main grid. Economic analysis methods for optimal sizing are proposed in $[93,94]$. Economic indices include

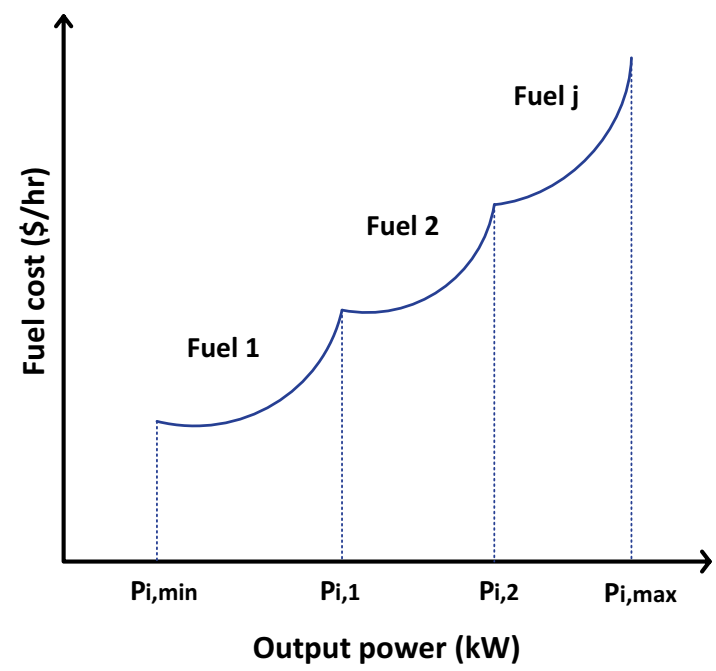

Fig. 6 Multi-fuel options with valve-point loading effects

Fig. 5 Fuel cost curve with prohibited zones 
Table 4 Costs that are related to MG sizing

\begin{tabular}{|c|c|}
\hline Cost & Details \\
\hline Levelized cost & $\begin{array}{l}\text { In [79], PSO seeks to determine the optimal size of an HRES that is composed of a WT, PV } \\
\text { arrays and battery energy storage. The objectives are to minimize the system cost based on the } \\
\text { levelized cost and to ensure the reliability of the system while satisfying technical constraints }\end{array}$ \\
\hline Net present value & $\begin{array}{l}\text { The objective of [95] is to optimize the size of the MG component to maximize the economic } \\
\text { benefits, such as the net present value. The MG is composed of a WT, a PV and battery energy } \\
\text { storage }\end{array}$ \\
\hline $\begin{array}{l}\text { Systems costs: annualized cost of invest- } \\
\text { ments, replacement, and maintenance, and } \\
\text { loss of load costs }\end{array}$ & $\begin{array}{l}\text { PSO is used to design a hybrid wind/PV/fuel cell system in [96]. The objectives are to find the } \\
\text { lowest cost and to ensure the reliability of the system for a period of } 20 \text { years. The simulation is } \\
\text { conducted over a year with a 1-h time step }\end{array}$ \\
\hline $\begin{array}{l}\text { Net present costs (NPCs): capital, replace- } \\
\text { ment and OM costs }\end{array}$ & $\begin{array}{l}\text { The authors in [82] apply PSO to find a suitable size that minimizes the net present costs of the } \\
\text { system. The objective function includes all NPCs from fuel cells, WT, electrolyzers, reformers, } \\
\text { anaerobic reactors, hydrogen tanks, and converters }\end{array}$ \\
\hline Cost of energy and total net present cost & $\begin{array}{l}\text { In [97], PSO is used to find the optimal size of a PV/diesel/biogas generator/biomass generator/ } \\
\text { micro hydro generator/battery for } 25 \text { years of operation. The cost of energy is the key param- } \\
\text { eter to be minimized under specified reliability criteria (expected energy not supplied) and } \\
\text { economic criteria (net present costs), renewable factor and emission of } \mathrm{CO}_{2} \text {. The objective is to } \\
\text { find a suitable combination of a hybrid system that ensures the lowest cost of energy }\end{array}$ \\
\hline $\begin{array}{l}\text { Maintenance costs, operating costs, invest- } \\
\text { ment costs, cost of purchasing power from } \\
\text { the DG owner and cost of buying power }\end{array}$ & $\begin{array}{l}\text { In [76], the authors propose MOPSO for determining the optimal location, size, and electricity } \\
\text { generation price of DG. The optimization objective is to maximize the benefit of DG while } \\
\text { minimizing the cost to the distribution company }\end{array}$ \\
\hline
\end{tabular}

from the substation

Present value of the total profit, present value of the maintenance costs, capital costs.

In [98], the objective of the PSO is to identify optimal parameter values for PV module installation, including the number of PV modules, their tilt angles, the placement of the PV modules and the distribution of the PV modules among the DC/AC converters. The optimization aims at maximizing the net profit over the total operation lifetime

System costs: investment, maintenance, fuel, Reference [99] introduces PSO for sizing the HRES. The strategy is to solve an MOO via the and replacement costs

$\varepsilon$-constraint approach. The total system costs are represented as an objective function, and LOLP and $\mathrm{CO}_{2}$ emissions are regarded as constraints. The objective is to minimize the system costs while minimizing the emissions and LOLP

Benefit: cost of electricity and heat sales and cost benefit of load reduction

The authors in [100] seek to determine the optimal types, sizes, and placement of DERs with the objective of maximizing the benefit-to-cost ratio of MG via the PSO technique. The MG system includes microturbines, DUs, and heat combustion turbines

The costs include capital, replacement, operation, maintenance, and production costs for MG and DG.

The authors in [101] employ PSO to design an MG that includes various numbers of PVs, WTs, and batteries. The objective was to find the lowest cost of MG construction based on the pool and bilateral-hybrid electricity markets

Depreciation cost of the battery

Reference [102] presents an improved hybrid GA-PSO for the multi-objective optimization of the siting and sizing of an MG in consideration of an EV. The objective is to minimize the power losses, voltage fluctuation, EV charging demand, and battery depreciation cost

the generation and installation costs and the cost benefits during the lifetime and the payback period. The costs of MG sizing are summarized in Table 4.

\section{Implementation of PSO for cost minimization in MG operations}

Many challenges are encountered in operating an MG with high economic benefits. However, many research studies are being conducted to overcome these issues. Thus, it is necessary to have an overview of the MG operations. In this section, energy management optimization problems, including ED, UC, and OPF, are outlined.

\section{Energy management}

Depending on the study objectives, energy management problems can cover the MG's supply (energy generation) or demand (energy consumption) side, or the whole system. Various optimization strategies for energy management have been proposed in the literature. These optimization strategies are mostly focused on cost minimization, including maintenance, operating and fuel costs and energy purchases.

The authors in [103] implement a PSO for real-time EMS in an MG. The simulation is updated every $3 \mathrm{~min}$. The objective is to minimize the total energy cost of the system. The 
authors have compared the performance of PSO with that of the sequential quadratic programming method.

The MOPSO is applied in [104] to determine the optimal configuration and sizes of the MG components for ensuring the reliability and cost effectiveness of the system. The study seeks to minimize the cost of electricity and the loss of power supply probability.

Reference [105] employs PSO to minimize the total operating costs of an MG. The optimization considers the bids and market prices of power exchanges between the MG and the main grid.

PSO is developed for real-time multi-objective optimization in [106]. The process is updated every $30 \mathrm{~s}$ over a period of $24 \mathrm{~h}$. The objective is to reduce the gas emissions and energy costs. The results demonstrate that the two objectives are in conflict (if the cost is low, the emissions are high, and vice versa). The simulation was conducted under two optimization techniques, namely, PSO and GA, using the MATLAB tool. The results demonstrate that PSO outperforms GA in terms of computation time.

In [107], the EMS is based on regrouping PSO (RegPSO) with the scheduling of the day ahead. The study is conducted under two scenarios of MG operation: isolated grid and gridconnected. The objective is to minimize the fuel and OM costs and the purchase cost from the utility while maximizing the profits from selling energy to the utility. The result demonstrates that RegPSO yields a better and faster solution than the GA-based approach.

A multi-objective PSO approach is presented for the system configuration and sizing of each location in [54]. The EMS defines the optimal operation of an MG with three conflicting objectives, such as reliability, operating cost and environmental impact.

The authors in [61] propose fuzzy self-adaptive PSO for minimizing the total operating cost and pollutant emissions. To evaluate the performance of the proposed method, they compare the results with those of classic PSO and GA under various scenarios of MG operation.

A real-time EMS that is based on binary PSO is proposed for both energy suppliers and users in [108]. The binary PSO defines the ON/OFF operation of home appliances to identify the lowest electricity tariff and to avoid a peak load.

Reference [109] develops an improved PSO (IPSO) algorithm for home energy management systems in a smart grid. The proposed algorithm minimizes electricity payments and peak loads.

In [110], PSO is applied to an HRES for electricity and water supply in a small village in Nigeria. The optimization aims at minimizing the energy cost of the system by saving on fuel costs. The study is conducted in two operating modes: using RES with diesel engines and using only RES.

EMS-based self-adaptive modified theta PSO is introduced in [111] for the minimization of the operating costs, including the fuel and start-up costs and the power exchange between the MG and the main grid. This study also examined a probabilistic framework that is based on the $2 \mathrm{~m}$ point estimate method, which depends on the uncertainty of the RES, the load forecast and the market characteristics.

The authors in [112] describe an EMS-based PSO with three objective functions: to minimize ESS operating costs; to maximize ESS efficiency; and to minimize the lifetime degradation of the ESS. The simulation was conducted for three cases according to each objective function. The simulations are compared by focusing on three criteria: operating costs, efficiency, and lifetime degradation.

Hybrid PSO and pattern search are applied to optimize the design and operation of an MG in [1]. To evaluate the performance of this method, four parameters are considered as key performance indicators (KPIs): cost, reliability, quality, and environmental impact. Each parameter is scaled from 1 to 10 based on the KPI grading. The cost function is comprised of capital, OM and generation costs. The objective is to find the minimum generation cost with the lowest total sum of the overall KPIs.

In [113], the authors use PSO to overcome a master-slave objective function, with the objective of determining the optimal type, size and operation of a smart MG. The master-slave function is based on net present value.

The combination of guaranteed-convergence PSO with Gaussian mutation (GPSO-GM) is reported in [114] for identifying the optimal size and operation of MG systems. The objective is to minimize the capital investment and generation costs. The role of Gaussian mutation and guaranteed convergence is to ensure the accuracy of the results.

\section{Economic dispatch}

ED determines the power output of each unit and uses it to find the lowest operating cost while satisfying equality and inequality constraints. ED problems are typically nonlinear. Since classical optimization techniques have difficultly addressing this problem, the application of the AI technique is inevitable. PSO is the most popular approach for solving ED problems due to its fast convergence.

The authors investigate the use of PSO to solve an ED for an MG in [115-117]. The optimization objective is to minimize the cost function while considering the fuel, operation and maintenance costs. The optimization problem is defined by a nonlinear function that includes equality and nonequality constraints.

The ED within an MG is solved in [118] using PSO to find the lowest operating cost and emission levels. The operating cost involves both the energy that is sold and the energy that is purchased from the utility. 
The authors in [119] study the cost minimization of multiple MGs, including RESs. The modified ED is fixed by PSO. The combination of two or more MGs limits the use of conventional generation and offers substantial economic benefits from RESs. The optimization objective is to find the lowest operating cost using the optimal schedule of a generation unit. The simulation is conducted under two scenarios, namely, with and without multiple MGs, for comparison in terms of the cost effectiveness.

A PSO is reported in [120] for minimizing the cost of the power that is produced by multiple MGs in the interactions with the main grid. The objective function considers the power generation, operation and maintenance costs and the purchase and sale of energy. The study considers a stochastic and probabilistic model of RES and load data in the optimization process.

Reference [121] proposes a stochastic ED model that incorporates wind and pumped storage generators, in addition to the thermal generators. The objective of this paper is to address the proposed stochastic ED problem via the modified PSO method.

\section{Unit commitment}

The unit commitment (UC) determines the ON/OFF schedule of generating units in a time frame over a scheduling period. It is formulated as a nonlinear optimization problem with $0 / 1$ variables that represent $\mathrm{ON} / \mathrm{OFF}$ status. UC plays an important role in MG planning for cost minimization. Frequent start-ups and shut-downs have a negative influence on the lifetimes of components, thereby resulting in an increase of the MG operating costs. The committed units should satisfy the production and demand forecasts.

The authors in [122] focus on a probabilistic UC model for MG operation, which includes the uncertainties of RESs and electric vehicles. The PSO is used to maximize the profit of UC in an MG. The results demonstrate the effects of plug-in electric vehicles on MG operating costs, and the performances of the probabilistic and deterministic UCs are compared.

Reference [123] combines binary PSO with the Lagrange multiplier method to minimize the energy costs in UC with consideration of electric vehicles and vehicle-to-grid (V2G). The constraint of UC with V2G is considered in the optimization problem. A comparison is conducted between two cases of UC: with and without V2G.

A combination method of weighted improved crazy PSO with pseudo code is presented in [124] for solving a UC problem. The objective is to find a compromise between energy costs and gas emissions. Using a weighted sum method, the MOO is converted to a single-objective optimization to minimize the operating costs. The performance result of this proposed approach is compared with those of other PSO forms, such as classic PSO and weighted improved PSO. The use of this approach guarantees the optimal solution and fast convergence speed.

In [125], the UC is solved via quantum-inspired BPSO (QBPSO), and the primal-dual interior point method is used to solve ED problems. The objective is to find a trade-off between the operation costs and emissions. Satisfactory accuracy of the solution and satisfactory calculation speed have been realized using the proposed method. It is concluded that this method is suitable for solving large-scale wind energy generation problems.

Reference [126] analyzes the UC and ED problems of thermal generation units with RES. The unit start/stop selection is performed using a priority list (PL), and PSO determines the optimal power flow, which is used to minimize the fuel costs of thermal units. PL-PSO is compared with PL-GA and DP. PL-PSO is guaranteed to find the optimal solution in minimal computation time.

In [72], the UC of thermal-unit-integrated wind and solar power is solved via GA-operated PSO. The combination of GA with PSO ensures the speedy convergence of the optimization solution. The solution to the cost minimization problem is guaranteed with the proposed method, in contrast to GA, the integer coded genetic algorithm (ICGA), and the Lagrangian relaxation and genetic algorithm (LRGA).

The authors in [127] formulate the optimization problem in two stages: the first stage consists of UC and the second of OPF. The BPSO is applied to select an ON/OFF schedule for thermal units. The proposed technique aims at minimizing the energy cost and identifying a secure optimal UC schedule for thermal units with a solar power plant in gridconnected mode.

In [128], the hybrid differential evolution/evolutionary programming/PSO algorithm is proposed for solving the UC problem of wind and thermal generation to obtain the minimum energy cost. The study analyzes the day-ahead UC scheduling of thermal units via a stochastic approach for wind power generation. The results demonstrate that this approach is more robust than a deterministic approach.

\section{Optimal power flow}

The OPF determines the optimal operation of MG, especially for minimizing the operating cost. The optimization constraints may include voltage or power, or other variables that do not exceed the production capacity limits.

The OPF is typically a nonlinear and nonconvex optimization problem. The nonconvexity is due to the power flow and the quadratic equality constraints [129]. Thus, it is not easy to solve this problem. A nonlinear optimization technique is needed for solving a nonlinear problem. For a nonconvex problem, the relaxation method can be used to convert it to a convex problem. However, in some cases, the 
convex relaxation is not exact. The solution to the relaxed problem could differ from the solution to the original problem [130].

The authors in [131] introduce a discrete PSO, namely, jumping frog PSO (JFPSO), and OPF for overcoming the sitting and sizing problem of DG units. The study aims at minimizing the operating cost by considering various technical constraints, such as voltage limits, thermal limits on lines and transformers, operational and planning limits and a maximum level of penetration of DG. JFPSO is used to determine the locations of the DG units and OPF is used to optimize the capacity of the DG units.

In [132], PSO with a time-varying acceleration coefficient (PSO-TVAC) and backward forward sweep (BFS) is used to solve an online OPF by considering EV charging/discharging, load curtailment and grid exchange. The objective of the first strategy is to minimize the operating cost, and that of the second strategy is to maximize profits. These two strategies are compared in terms of the total cost benefit, which is calculated as the difference between revenue and expense.

PSO is applied in [133] to solve the OPF problem in multiple MGs. The study focuses on cost minimization by comparing the performance results between PSO and GA. The results demonstrate that PSO realizes the best convergence performance. Hence, PSO is more efficient for cost optimization in ED problems than GA.

Reference [134] uses PSO to solve the OPF problem of two MGs, which are each comprised of a controllable load, PV, WT, and BESS. The objectives are to reduce the costs and to shave peak loads of MG systems.

\section{Conclusion}

The MG is one of the fastest growing energy sectors, although the cost of the electricity that is generated by it remains high. Therefore, it is important to identify efficient sizing and operation methods to reduce the cost of the electricity. Additionally, due to environmental problems, we are forced to search for strategies that use combustible sources more efficiently. Furthermore, MGs have been demonstrated to be a powerful technology that makes cities and communities more sustainable and resilient.

This paper summarizes research developments and the implementation of PSO algorithms in renewable energy systems. Since a general introduction to MGs has been provided, economic analysis is considered a key factor in this paper. This survey of an economic tool for MG operations and sizing can be useful for research on MGs and other power systems.

Throughout this review, comments provide a deeper understanding of cost analysis in MG optimization. Various types of cost functions that are used in MG optimization are presented. Cost minimization approaches have been outlined according to the supply or demand side, such as EMS, ED, $\mathrm{UC}$, and ED. Thus, the features of sizing and operations for cost minimization are analyzed, and they include planning and scheduling problems, with the objective of minimizing the cost.

Open Access This article is licensed under a Creative Commons Attribution 4.0 International License, which permits use, sharing, adaptation, distribution and reproduction in any medium or format, as long as you give appropriate credit to the original author(s) and the source, provide a link to the Creative Commons licence, and indicate if changes were made. The images or other third party material in this article are included in the article's Creative Commons licence, unless indicated otherwise in a credit line to the material. If material is not included in the article's Creative Commons licence and your intended use is not permitted by statutory regulation or exceeds the permitted use, you will need to obtain permission directly from the copyright holder. To view a copy of this licence, visit http://creativecommons.org/licenses/by/4.0/.

\section{References}

1. Gabbar, H.A., Labbi, Y., Bower, L., Pandya, D.: Performance optimization of integrated gas and power within microgrids using hybrid PSO-PS algorithm. Int. J. Energy Res. 40(7), 971-982 (2016)

2. Zhang, Y., Gatsis, N., Giannakis, G.B.: Robust distributed energy management for microgrids with renewables. In: Smart Grid Communications (SmartGridComm), 2012 IEEE Third International Conference on 2012, pp. 510-515. IEEE

3. Maulik, A., Das, D.: Optimal operation of microgrid using four different optimization techniques. Sustain. Energy Technol. Assess. 21, 100-120 (2017)

4. Fadaee, M., Radzi, M.: Multi-objective optimization of a standalone hybrid renewable energy system by using evolutionary algorithms: a review. Renew. Sustain. Energy Rev. 16(5), 33643369 (2012)

5. Fathima, A.H., Palanisamy, K.: Optimization in microgrids with hybrid energy systems - a review. Renew. Sustain. Energy Rev. 45, 431-446 (2015)

6. Dawoud, S.M., Lin, X., Okba, M.I.: Hybrid renewable microgrid optimization techniques: a review. Renew. Sustain. Energy Rev. 82, 2039-2052 (2018)

7. Hossain, E., Kabalci, E., Bayindir, R., Perez, R.: Microgrid testbeds around the world: state of art. Energy Convers. Manag. 86, 132-153 (2014)

8. Wang, C., Nehrir, H., Lin, F., Zhao, J.: From hybrid energy systems to microgrids: hybridization techniques, configuration, and control. In: Power and Energy Society General Meeting, 2010 IEEE 2010, pp. 1-4. IEEE

9. Ackermann, T., Andersson, G., Söder, L.: Distributed generation: a definition1. Electr. Power Syst. Res. 57(3), 195-204 (2001)

10. Zenginis, I., Vardakas, J.S., Echave, C., Morató, M., Abadal, J., Verikoukis, C.V.: Cooperation in microgrids through power exchange: an optimal sizing and operation approach. Appl. Energy 203, 972-981 (2017)

11. Fossati, J.P., Galarza, A., Martín-Villate, A., Fontán, L.: A method for optimal sizing energy storage systems for microgrids. Renew. Energy 77, 539-549 (2015)

12. Das, C.K., Bass, O., Kothapalli, G., Mahmoud, T.S., Habibi, D.: Overview of energy storage systems in distribution networks: 
placement, sizing, operation, and power quality. Renew. Sustain. Energy Rev. 91, 1205-1230 (2018)

13. Fentis, A., Bahatti, L., Tabaa, M., Mestari, M.: Short-term nonlinear autoregressive photovoltaic power forecasting using statistical learning approaches and in situ observations. Int. J. Energy Environ. Eng. 10(2), 189-206 (2019)

14. Sobu, A., Wu, G.: Optimal operation planning method for isolated micro grid considering uncertainties of renewable power generations and load demand. In: Innovative Smart Grid Technologies-Asia (ISGT Asia), 2012 IEEE 2012, pp. 1-6. IEEE

15. Badar, A., Umre, B., Junghare, A.: Study of artificial intelligence optimization techniques applied to active power loss minimization. IOSR J. Electr. Electron. Eng. 20, 1278-1676 (2014)

16. Bello, O., Holzmann, J., Yaqoob, T., Teodoriu, C.: Application of artificial intelligence methods in drilling system design and operations: a review of the state of the art. J. Artif. Intell. Soft Comput. Res. 5(2), 121-139 (2015)

17. Biao, S., Chang Hua, H., Xin Hua, Y., Chuan, H.: Mutation particle swarm optimization algorithm for solving the optimal operation model of thermal power plants. J. Renew. Sustain. Energy 6(4), 043118 (2014)

18. Diab, A.A.Z., Sultan, H.M., Mohamed, I.S., Kuznetsov, O.N., Do, T.D.: Application of different optimization algorithms for optimal sizing of PV/wind/diesel/battery storage stand-alone hybrid microgrid. IEEE Access. 7, 119223-119245 (2019)

19. de Andrade, C.F., dos Santos, L.F., Macedo, M.V.S., Rocha, P.A.C., Gomes, F.F.: Four heuristic optimization algorithms applied to wind energy: determination of Weibull curve parameters for three Brazilian sites. Int. J. Energy Environ. Eng. 10(1), 1-12 (2019)

20. Anoune, K., Bouya, M., Astito, A., Abdellah, A.B.: Sizing methods and optimization techniques for PV-wind based hybrid renewable energy system: a review. Renew. Sustain. Energy Rev. 93, 652-673 (2018)

21. Khan, F.A., Pal, N., Saeed, S.H.: Review of solar photovoltaic and wind hybrid energy systems for sizing strategies optimization techniques and cost analysis methodologies. Renew. Sustain. Energy Rev. 92, 937-947 (2018)

22. Emad, D., El-Hameed, M., Yousef, M., El-Fergany, A.: Computational methods for optimal planning of hybrid renewable microgrids: a comprehensive review and challenges. Arch. Comput. Methods Eng. 20, 1-23 (2019)

23. Twaha, S., Ramli, M.A.: A review of optimization approaches for hybrid distributed energy generation systems: off-grid and grid-connected systems. Sustain. Cities Soc. 41, 320-331 (2018)

24. Iqbal, M., Azam, M., Naeem, M., Khwaja, A., Anpalagan, A.: Optimization classification, algorithms and tools for renewable energy: a review. Renew. Sustain. Energy Rev. 39, 640-654 (2014)

25. Gamarra, C., Guerrero, J.M.: Computational optimization techniques applied to microgrids planning: a review. Renew. Sustain. Energy Rev. 48, 413-424 (2015)

26. Kumar, P., Pukale, R.: Optimal power flow using PSO. Computational Intelligence in Data Mining, vol. 1, pp. 109-121. Springer, Berlin (2015)

27. Turkay, B.E., Cabadag, R.I.: Optimal power flow solution using particle swarm optimization algorithm. In: EUROCON, 2013 IEEE 2013, pp. 1418-1424. IEEE

28. Zhang, Y., Wang, S., Ji, G.: A comprehensive survey on particle swarm optimization algorithm and its applications. Mathematical Problems in Engineering 2015 (2015)

29. Del Valle, Y., Venayagamoorthy, G.K., Mohagheghi, S., Harley, R.G., Hernandez, J.: Particle swarm optimization: basic concepts, variants and applications in power systems (2008)
30. Cao, T., Hwang, Y., Radermacher, R.: Development of an optimization based design framework for microgrid energy systems. Energy 140, 340-351 (2017)

31. Kanchev, H., Francois, B., Lazarov, V.: Unit commitment by dynamic programming for microgrid operational planning optimization and emission reduction. In: Electrical Machines and Power Electronics and 2011 Electromotion Joint Conference (ACEMP), 2011 International Aegean Conference on 2011, pp. 502-507. IEEE

32. Tsikalakis, A., Hatziargyriou, N.: Environmental benefits of distributed generation with and without emissions trading. Energy Policy 35(6), 3395-3409 (2007)

33. Moradi, M.H., Eskandari, M., Showkati, H.: A hybrid method for simultaneous optimization of DG capacity and operational strategy in microgrids utilizing renewable energy resources. Int. J. Electr. Power Energy Syst. 56, 241-258 (2014)

34. Kirthiga, M.V., Daniel, S.A., Gurunathan, S.: A methodology for transforming an existing distribution network into a sustainable autonomous micro-grid. IEEE Trans. Sustain. Energy 4(1), 31-41 (2013)

35. Afzalan, E., Taghikhani, M., Sedighizadeh, M.: Optimal placement and sizing of DG in radial distribution networks using SFLA. Int. J. Energy Eng. 2(3), 73-77 (2012)

36. El-Ela, A.A., Allam, S.M., Shatla, M.: Maximal optimal benefits of distributed generation using genetic algorithms. Electr. Power Syst. Res. 80(7), 869-877 (2010)

37. Ciez, R.E., Whitacre, J.: Comparative techno-economic analysis of hybrid micro-grid systems utilizing different battery types. Energy Convers. Manag. 112, 435-444 (2016)

38. Ju, C., Wang, P., Goel, L., Xu, Y.: A two-layer energy management system for microgrids with hybrid energy storage considering degradation costs. IEEE Trans. Smart Grid 9(6), 6047 (2017)

39. Anvari-Moghaddam, A., Dragicevic, T., Vasquez, J.C., Guerrero, J.M.: Optimal utilization of microgrids supplemented with battery energy storage systems in grid support applications. In: DC Microgrids (ICDCM), 2015 IEEE First International Conference on 2015, pp. 57-61. IEEE

40. Oudalov, A., Cherkaoui, R., Beguin, A.: Sizing and optimal operation of battery energy storage system for peak shaving application. In: Power Tech, 2007 IEEE Lausanne 2007, pp. 621-625. IEEE

41. Chen, S., Gooi, H.B., Wang, M.: Sizing of energy storage for microgrids. IEEE Trans. Smart Grid 3(1), 142-151 (2012)

42. Nguyen, D.T., Le, L.B.: Risk-constrained profit maximization for microgrid aggregators with demand response. IEEE Trans. Smart Grid 6(1), 135-146 (2015)

43. Arefifar, S.A., Mohamed, Y.A.-R.I.: DG mix, reactive sources and energy storage units for optimizing microgrid reliability and supply security. IEEE Trans. Smart Grid 5(4), 1835-1844 (2014)

44. Luna-Rubio, R., Trejo-Perea, M., Vargas-Vázquez, D., RíosMoreno, G.: Optimal sizing of renewable hybrids energy systems: a review of methodologies. Sol. Energy 86(4), 1077-1088 (2012)

45. Bedon, G., Castelli, M.R., Benini, E.: Optimization of a Darrieus vertical-axis wind turbine using blade element-momentum theory and evolutionary algorithm. Renew. Energy 59, 184-192 (2013)

46. Pérez, B., Mínguez, R., Guanche, R.: Offshore wind farm layout optimization using mathematical programming techniques. Renew. Energy 53, 389-399 (2013)

47. Aman, M., Jasmon, G., Bakar, A., Mokhlis, H.: A new approach for optimum simultaneous multi-DG distributed generation Units placement and sizing based on maximization of system loadability using HPSO (hybrid particle swarm optimization) algorithm. Energy 66, 202-215 (2014) 
48. Schwaegerl, C., Tao, L., Mancarella, P., Strbac, G.: A multiobjective optimization approach for assessment of technical, commercial and environmental performance of microgrids. Eur. Trans. Electr. Power 21(2), 1269-1288 (2011)

49. Boloukat, M.H.S., Foroud, A.A.: Stochastic-based resource expansion planning for a grid-connected microgrid using interval linear programming. Energy 113, 776-787 (2016)

50. Zhao, M., Chen, Z., Blaabjerg, F.: Optimisation of electrical system for offshore wind farms via genetic algorithm. IET Renew. Power Gener. 3(2), 205-216 (2009)

51. Zghal, W., Kantchev, G., Kchaou, H.: Optimization and management of the energy produced by a wind energizing system. Renew. Sustain. Energy Rev. 15(2), 1080-1088 (2011)

52. Alsayed, M., Cacciato, M., Scelba, G., Consoli, A.: Optimal sizing of hybrid power generation systems based on multi criteria decision analysis. In: International Symposium on Power Electronics Power Electronics, Electrical Drives, Automation and Motion, 20-22 June 2012, pp. 1442-1447

53. Kaabeche, A., Belhamel, M., Ibtiouen, R.: Sizing optimization of grid-independent hybrid photovoltaic/wind power generation system. Energy 36(2), 1214-1222 (2011)

54. Azaza, M., Wallin, F.: Multi objective particle swarm optimization of hybrid micro-grid system: a case study in Sweden. Energy 123, 108-118 (2017)

55. Lin, N., Zhou, B., Wang, X.: Optimal placement of distributed generators in micro-grid. In: Consumer Electronics, Communications and Networks (CECNet), 2011 International Conference on 2011, pp. 4239-4242. IEEE

56. Zhang, D., Evangelisti, S., Lettieri, P., Papageorgiou, L.G.: Economic and environmental scheduling of smart homes with microgrid: DER operation and electrical tasks. Energy Convers. Manag. 110, 113-124 (2016)

57. Jebaraj, S., Iniyan, S., Goic, R.: An optimal electricity allocation model for sustainable resource use in India. Int. J. Energy Res. 37(8), 923-935 (2013)

58. Arnette, A., Zobel, C.W.: An optimization model for regional renewable energy development. Renew. Sustain. Energy Rev. 16(7), 4606-4615 (2012)

59. Koo, J., Han, K., Yoon, E.S.: Integration of CCS, emissions trading and volatilities of fuel prices into sustainable energy planning, and its robust optimization. Renew. Sustain. Energy Rev. 15(1), 665-672 (2011)

60. Alsayed, M., Cacciato, M., Scarcella, G., Scelba, G.: Multicriteria optimal sizing of photovoltaic-wind turbine grid connected systems. IEEE Trans. Energy Convers. 28(2), 370-379 (2013)

61. Moghaddam, A.A., Seifi, A., Niknam, T.: Multi-operation management of a typical micro-grids using particle swarm optimization: a comparative study. Renew. Sustain. Energy Rev. 16(2), 1268-1281 (2012)

62. Dey, B., Roy, S.K., Bhattacharyya, B.: Solving multi-objective economic emission dispatch of a renewable integrated microgrid using latest bio-inspired algorithms. Eng. Sci. Technol. Int. J. 22(1), 55-66 (2019)

63. Zhao, B., Zhang, X., Chen, J., Wang, C., Guo, L.: Operation optimization of standalone microgrids considering lifetime characteristics of battery energy storage system. IEEE trans. Sustain. Energy 4(4), 934-943 (2013)

64. Pourmousavi, S.A., Sharma, R.K., Asghari, B.: A framework for real-time power management of a grid-tied microgrid to extend battery lifetime and reduce cost of energy (2012)

65. Shadmand, M.B., Balog, R.S.: Multi-objective optimization and design of photovoltaic-wind hybrid system for community smart DC microgrid. IEEE Trans. Smart Grid 5(5), 2635-2643 (2014)

66. Zhang, M., Chen, J.: The energy management and optimized operation of electric vehicles based on microgrid. IEEE Trans. Power Deliv. 29(3), 1427-1435 (2014)
67. Shi, L., Luo, Y., Tu, G.: Bidding strategy of microgrid with consideration of uncertainty for participating in power market. Int. J. Electr. Power Energy Syst. 59, 1-13 (2014)

68. Hameed, A.M.H., Elhagri, M.T., Shaltout, A.A., Aziz, M.M.A.: Optimum sizing of hybrid WT/PV systems via open-space particle swarm optimization. In: 2012 Second Iranian Conference on Renewable Energy and Distributed Generation, 6-8 March 2012, pp. 55-60

69. Khodaei, A., Shahidehpour, M.: Microgrid-based co-optimization of generation and transmission planning in power systems. IEEE Trans. Power Syst. 28(2), 1582-1590 (2013)

70. Perera, A., Attalage, R., Perera, K., Dassanayake, V.: Designing standalone hybrid energy systems minimizing initial investment, life cycle cost and pollutant emission. Energy 54, 220-230 (2013)

71. Bahramirad, S., Reder, W., Khodaei, A.: Reliability-constrained optimal sizing of energy storage system in a microgrid. Perspectives 1, 3 (2012)

72. Chakraborty, S., Senjyu, T., Saber, A.Y., Yona, A., Funabashi, T.: Optimal thermal unit commitment integrated with renewable energy sources using advanced particle swarm optimization. IEEJ Trans. Electr. Electron. Eng. 4(5), 609-617 (2009)

73. Orero, S., Irving, M.: Large scale unit commitment using a hybrid genetic algorithm. Int. J. Electr. Power Energy Syst. 19(1), 45-55 (1997)

74. Mohamed, F.A., Koivo, H.N.: Microgrid online management and balancing using multiobjective optimization. In: Power Tech, 2007 IEEE Lausanne 2007, pp. 639-644. IEEE

75. Khan, A.A., Naeem, M., Iqbal, M., Qaisar, S., Anpalagan, A.: A compendium of optimization objectives, constraints, tools and algorithms for energy management in microgrids. Renew. Sustain. Energy Rev. 58, 1664-1683 (2016)

76. Ameli, A., Bahrami, S., Khazaeli, F., Haghifam, M.-R.: A multiobjective particle swarm optimization for sizing and placement of DGs from DG owner's and distribution company's viewpoints. IEEE Trans. Power Deliv. 29(4), 1831-1840 (2014)

77. Mao, M., Jin, P., Chang, L., Xu, H.: Economic analysis and optimal design on microgrids with SS-PVs for industries. IEEE Trans. Sustain. Energy 5(4), 1328-1336 (2014)

78. Chen, C., Duan, S., Cai, T., Liu, B., Hu, G.: Optimal allocation and economic analysis of energy storage system in microgrids. IEEE Trans. Power Electron. 26(10), 2762-2773 (2011)

79. Mohamed, M.A., Eltamaly, A.M., Alolah, A.I.: PSO-based smart grid application for sizing and optimization of hybrid renewable energy systems. PLoS One 11(8), e0159702 (2016)

80. Dufo-López, R., Bernal-Agustín, J.L., Yusta-Loyo, J.M., Domínguez-Navarro, J.A., Ramírez-Rosado, I.J., Lujano, J., Aso, I.: Multi-objective optimization minimizing cost and life cycle emissions of stand-alone PV-wind-diesel systems with batteries storage. Appl. Energy 88(11), 4033-4041 (2011)

81. Kumar, Y.P., Bhimasingu, R.: Renewable energy based microgrid system sizing and energy management for green buildings. J. Mod. Power Syst. Clean Energy 3(1), 1-13 (2015)

82. Hakimi, S., Moghaddas-Tafreshi, S.: Optimal sizing of a standalone hybrid power system via particle swarm optimization for Kahnouj area in south-east of Iran. Renew. Energy 34(7), 1855-1862 (2009)

83. El-Naggar, K., AlRashidi, M., Al-Othman, A.: Estimating the input-output parameters of thermal power plants using PSO. Energy Convers. Manag. 50(7), 1767-1772 (2009)

84. Vanithasri, M., Balamurugan, R., Lakshminarasimman, L.: Modified radial movement optimization (MRMO) technique for estimating the parameters of fuel cost function in thermal power plants. Eng. Sci. Technol. Int. J. 19(4), 2035-2042 (2016) 
85. Park, J.-B., Lee, K.-S., Shin, J.-R., Lee, K.Y.: A particle swarm optimization for economic dispatch with nonsmooth cost functions. IEEE Trans. Power Syst. 20(1), 34-42 (2005)

86. Selvakumar, A.I., Thanushkodi, K.: A new particle swarm optimization solution to nonconvex economic dispatch problems. IEEE Trans. Power Syst. 22(1), 42-51 (2007)

87. Shayeghi, H., Ghasemi, A.: A modified artificial bee colony based on chaos theory for solving non-convex emission/economic dispatch. Energy Convers. Manag. 79, 344-354 (2014)

88. Basu, M.: Kinetic gas molecule optimization for nonconvex economic dispatch problem. Int. J. Electr. Power Energy Syst. 80, 325-332 (2016)

89. Vo, D.N., Schegner, P., Ongsakul, W.: Cuckoo search algorithm for non-convex economic dispatch. IET Gener. Trans. Distrib. 7(6), 645-654 (2013)

90. Park, J.-B., Jeong, Y.-W., Shin, J.-R., Lee, K.Y.: An improved particle swarm optimization for nonconvex economic dispatch problems. IEEE Trans. Power Syst. 25(1), 156-166 (2010)

91. Wang, L., Li, L.-P.: An effective differential harmony search algorithm for the solving non-convex economic load dispatch problems. Int. J. Electr. Power Energy Syst. 44(1), 832-843 (2013)

92. Binetti, G., Davoudi, A., Naso, D., Turchiano, B., Lewis, F.L.: A distributed auction-based algorithm for the nonconvex economic dispatch problem. IEEE Trans. Ind. Inf. 10(2), 11241132 (2014)

93. Khan, M.W., Wang, J., Ma, M., Xiong, L., Li, P., Wu, F.: Optimal energy management and control aspects of distributed microgrid using multi-agent systems. Sustain. Cities Soc. 20, 18 (2018)

94. Muthuvel, P., Daniel, S.A., Paul, S.K.: Sizing of PV array in a DC nano-grid for isolated households after alteration in time of consumption. Eng. Sci. Technol. Int. J. 20(6), 1632-1641 (2017)

95. Cavanini, L., Ciabattoni, L., Ferracuti, F., Ippoliti, G., Longhi, S.: Microgrid sizing via profit maximization: a population based optimization approach. In: Industrial Informatics (INDIN), 2016 IEEE 14th International Conference on 2016, pp. 663-668. IEEE

96. Kaviani, A.K., Riahy, G., Kouhsari, S.M.: Optimal design of a reliable hydrogen-based stand-alone wind/PV generating system, considering component outages. Renew. Energy 34(11), 2380-2390 (2009)

97. Upadhyay, S., Sharma, M.: Development of hybrid energy system with cycle charging strategy using particle swarm optimization for a remote area in India. Renew. Energy 77, 586-598 (2015)

98. Kornelakis, A., Marinakis, Y.: Contribution for optimal sizing of grid-connected PV-systems using PSO. Renew. Energy 35(6), 1333-1341 (2010)

99. Sharafi, M., ELMekkawy, T.Y.: Multi-objective optimal design of hybrid renewable energy systems using PSO-simulation based approach. Renew. Energy 68, 67-79 (2014)

100. Basu, A.K., Chowdhury, S., Chowdhury, S.: Impact of strategic deployment of CHP-based DERs on microgrid reliability. IEEE Trans. Power Deliv. 25(3), 1697-1705 (2010)

101. Mohammadi, M., Hosseinian, S., Gharehpetian, G.: Optimization of hybrid solar energy sources/wind turbine systems integrated to utility grids as microgrid (MG) under pool/bilateral/hybrid electricity market using PSO. Sol. Energy 86(1), 112-125 (2012)

102. Mozafar, M.R., Moradi, M.H., Amini, M.H.: A simultaneous approach for optimal allocation of renewable energy sources and electric vehicle charging stations in smart grids based on improved GA-PSO algorithm. Sustain. Cities Soc. 32, 627-637 (2017)

103. Pourmousavi, S.A., Nehrir, M.H., Colson, C.M., Wang, C.: Realtime energy management of a stand-alone hybrid wind-microturbine energy system using particle swarm optimization. IEEE Trans. Sustain. Energy 1(3), 193-201 (2010)
104. Borhanazad, H., Mekhilef, S., Ganapathy, V.G., Modiri-Delshad, M., Mirtaheri, A.: Optimization of micro-grid system using MOPSO. Renew. Energy 71, 295-306 (2014)

105. Radosavljević, J., Jevtić, M., Klimenta, D.: Energy and operation management of a microgrid using particle swarm optimization. Eng. Optim. 48(5), 811-830 (2016)

106. Litchy, A., Nehrir, M.: Real-time energy management of an islanded microgrid using multi-objective particle swarm optimization. In: PES General Meeting|Conference and Exposition, 2014 IEEE 2014, pp. 1-5. IEEE

107. Li, H., Eseye, A.T., Zhang, J., Zheng, D.: Optimal energy management for industrial microgrids with high-penetration renewables. Protect. Control Mod. Power Syst. 2(1), 12 (2017)

108. Zhou, Y., Chen, Y., Xu, G., Zheng, C., Chang, M.: Home energy management in smart grid with renewable energy resources. In: Computer Modelling and Simulation (UKSim), 2014 UKSim-AMSS 16th International Conference on 2014, pp. 351-356. IEEE

109. Yang, H.-T., Yang, C.-T., Tsai, C.-C., Chen, G.-J., Chen, S.-Y.: Improved PSO based home energy management systems integrated with demand response in a smart grid. In: Evolutionary Computation (CEC), 2015 IEEE Congress on 2015, pp. 275-282. IEEE

110. Stoppato, A., Cavazzini, G., Ardizzon, G., Rossetti, A.: A PSO (particle swarm optimization)-based model for the optimal management of a small PV (Photovoltaic)-pump hydro energy storage in a rural dry area. Energy 76, 168-174 (2014)

111. Baziar, A., Kavousi-Fard, A.: Considering uncertainty in the optimal energy management of renewable micro-grids including storage devices. Renew. Energy 59, 158-166 (2013)

112. García-Triviño, P., Llorens-Iborra, F., García-Vázquez, C.A., Gil-Mena, A.J., Fernández-Ramírez, L.M., Jurado, F.: Longterm optimization based on PSO of a grid-connected renewable energy/battery/hydrogen hybrid system. Int. J. Hydrog. Energy 39(21), 10805-10816 (2014)

113. Moradi, M.H., Eskandari, M., Hosseinian, S.M.: Operational strategy optimization in an optimal sized smart microgrid. IEEE Trans. Smart Grid 6(3), 1087-1095 (2015)

114. Abedini, M., Moradi, M.H., Hosseinian, S.M.: Optimal management of microgrids including renewable energy sources using GPSO-GM algorithm. Renew. Energy 90, 430-439 (2016)

115. Cerqueira, S., Saavedra, O., Lima, S.: Microgrid economic dispatch with storage systems by particle swarm optimization. In: XI Simposio Brasileiro de Automacao Inteligente 2015

116. Chen, Y., Zhang, J., Tang, Q., Lin, S.: The implementation of micro-grid economic dispatch based on particle swarm optimization. In: Chinese Automation Congress (CAC), 2015, pp. 1310-1315. IEEE

117. Mukherjee, S., Chakraborty, R., Goswami, S.K.: Economic generation scheduling in microgrid with pumped-hydro unit using particle swarm optimization. In: 2015 IEEE International Conference on Electrical, Computer and Communication Technologies (ICECCT), 5-7 March 2015, pp. 1-5

118. Karthikeyan, A., Manikandan, K., Somasundaram, P.: Economic dispatch of microgrid with smart energy storage systems using Particle Swarm Optimization. In: Computation of Power, Energy Information and Communication (ICCPEIC), 2016 International Conference on 2016, pp. 783-789. IEEE

119. Penangsang, O.: Economic dispatch of multi microgrid systems with renewable energy sources using particle swarm optimization. In: Intelligent Technology and Its Applications (ISITIA), 2016 International Seminar on 2016, pp. 595-600. IEEE

120. Nikmehr, N., Ravadanegh, S.N.: Optimal power dispatch of multi-microgrids at future smart distribution grids. IEEE Trans. Smart Grid 6(4), 1648-1657 (2015) 
121. Ramya, N., Babu, M.R., Sudhakar, T.: Solution of Stochastic Economic Dispatch Problem using Modified PSO Algorithm. Int. J. Comput. Appl 20, 18 (2013)

122. Tafreshi, S.M.M., Ranjbarzadeh, H., Jafari, M., Khayyam, H.: A probabilistic unit commitment model for optimal operation of plug-in electric vehicles in microgrid. Renew. Sustain. Energy Rev. 66, 934-947 (2016)

123. Jin, L., Yang, H., Cheng, F., Zhou, Y., Zhao, R.: A novel approach for the unit commitment with vehicle-to-grid. In: 2012 15th International Conference on Electrical Machines and Systems (ICEMS), 21-24 Oct. 2012, pp. 1-6

124. Shukla, A., Singh, S.N.: Multi-objective unit commitment with renewable energy using hybrid approach. IET Renew. Power Gener. 10(3), 327-338 (2016)

125. Wu, X., Zhang, B., Li, J., Luo, G., Duan, Y., Wang, K.: Solving power system unit commitment with wind farms using multiobjective quantum-inspired binary particle swarm optimization. J. Renew. Sustain. Energy 5(2), 021410 (2013)

126. Alam, M.S., Kiran, B.D.H., Kumari, M.S.: Priority list and particle swarm optimization based unit commitment of thermal units including renewable uncertainties. In: Power System Technology (POWERCON), 2016 IEEE International Conference on 2016, pp. 1-6. IEEE

127. Gaddam, R.R., Jain, A., Belede, L.: A PSO based smart unit commitment strategy for power systems including solar energy. In: Proceedings of Seventh International Conference on Bio-Inspired Computing: Theories and Applications (BIC-TA 2012) 2013, pp. 531-542. Springer

128. Pinto, R., Carvalho, L.M., Sumaili, J., Pinto, M.S., Miranda, V.: Coping with wind power uncertainty in unit commitment: a robust approach using the new hybrid metaheuristic deepso. In: PowerTech, 2015 IEEE Eindhoven 2015, pp. 1-6. IEEE

129. Radziukynas, V., Radziukyniene, I.: Optimization methods application to optimal power flow in electric power systems. In: Radziukynas, V. (ed.) Optimization in the Energy Industry, pp. 409-436. Springer, Berlin (2009)

130. Frank, S., Steponavice, I., Rebennack, S.: Optimal power flow: a bibliographic survey I. Energy Syst. 3(3), 221-258 (2012)

131. Gomez-Gonzalez, M., López, A., Jurado, F.: Optimization of distributed generation systems using a new discrete PSO and OPF. Electr. Power Syst. Res. 84(1), 174-180 (2012)

132. Mohan, V., Suresh, M.R., Singh, J.G., Ongsakul, W., Kumar, B.K.: Online optimal power management considering electric vehicles, load curtailment and grid trade in a microgrid energy market. In: Innovative Smart Grid Technologies-Asia (ISGT ASIA), 2015 IEEE 2015, pp. 1-6. IEEE

133. Pisei, S., Choi, J.-Y., Lee, W.-P., Won, D.-J.: Optimal power scheduling in multi-microgrid system using particle swarm optimization. J. Electr. Eng. Technol. 12(4), 1329-1339 (2017)

134. Sortomme, E., El-Sharkawi, M.: Optimal power flow for a system of microgrids with controllable loads and battery storage. In: Power Systems Conference and Exposition, 2009. PSCE'09. IEEE/PES 2009, pp. 1-5. IEEE

Publisher's Note Springer Nature remains neutral with regard to jurisdictional claims in published maps and institutional affiliations. 